\title{
Do Parents Synchronise Nest Visits as an Antipredator Adaptation in Birds of New Zealand and Tasmania?
}

\author{
Nyil Khwaja ${ }^{1,2 \star}$, Melanie Massaro ${ }^{1,3}$, Thomas E. Martin ${ }^{4}$ and James V. Briskie ${ }^{1}$ \\ ${ }^{1}$ School of Biological Sciences, University of Canterbury, Christchurch, New Zealand, ${ }^{2}$ BirdLife Australia, Broome Bird \\ Observatory, Broome, WA, Australia, ${ }^{3}$ School of Environmental Sciences, Institute for Land, Water and Society, Charles Sturt \\ University, Albury, NSW, Australia, ${ }^{4}$ U.S. Geological Survey, Montana Cooperative Wildlife Research Unit, University of \\ Montana, Missoula, MT, United States
}

OPEN ACCESS

Edited by:

Rufus Johnstone University of Cambridge,

United Kingdom

Reviewed by:

Gretchen F. Wagner,

Netherlands Institute of Ecology

(NIOO-KNAW), Netherlands

Simon Charles Griffith

Macquarie University, Australia

*Correspondence:

Nyil Khwaja

nyil.khwaja@cantab.net

Specialty section:

This article was submitted to Behavioral and Evolutionary Ecology,

a section of the journal

Frontiers in Ecology and Evolution

Received: 29 April 2019 Accepted: 27 September 2019

Published: 11 October 2019

Citation:

Khwaja N, Massaro M, Martin TE and

Briskie JV (2019) Do Parents

Synchronise Nest Visits as an

Antipredator Adaptation in Birds of

New Zealand and Tasmania?

Front. Ecol. Evol. 7:389.

doi: 10.3389/fevo.2019.00389
Birds with altricial offspring need to feed them regularly, but each feeding visit risks drawing attention to the nest and revealing its location to potential predators. Synchronisation of visits by both parents has been suggested as a behavioural adaptation to reduce the risk of nest predation. Under this hypothesis, higher risk of nest predation favours greater synchrony of parental feeding visits. We investigated this prediction over three timescales using nestling provisioning data from 25 passerine species in Tasmania and New Zealand. We estimated the extent to which parents actively synchronised their visits to the nest by comparing observed patterns of synchrony with those expected to occur at random. We found that in general, species did not synchronise visits more often than expected by chance. Species varied in the tendency to synchronise visits, but this variation was not explained by likely predation pressure in the distant evolutionary past: New Zealand endemic species, which evolved in the absence of mammalian nest predators, synchronised their visits as often as species which evolved with more diverse predatory guilds. Nest predation risk has increased over time in New Zealand due to introduced predators, but synchrony in visits also was not explained by manipulated predation risk: visit synchrony was equivalent between a predator-removal site and a site where predators remained. However, within one New Zealand species, visit synchrony was higher for mainland populations, which have been exposed to predatory mammals for $c .800$ years, than for a population on an offshore island to which predatory mammals were never introduced. We conclude that breeding birds may have some capacity to adapt the synchrony with which they provision over short evolutionary timescales. However, the lack of synchrony in most species suggests that either asynchrony provides benefits that outweigh the greater risk of predation, or synchrony incurs costs not compensated by reduced predation.

Keywords: Anthornis melanura, bellbird, comparative analysis, coordination, invasive species, synchronisation, synchronise, synchronised

\section{INTRODUCTION}

Avoiding nest predation is a vital component of reproductive success for bird species with altricial offspring. As the risk of nest predation increases, so should the strength of selection favouring adaptations that mitigate or reduce this risk. Evidence suggests predation risk has had a notable role in the evolution of behavioural and life history traits in both breeding and nestling 
birds (Martin and Briskie, 2009). For example, increased nest predation pressure across species is correlated with shorter breeding periods, reduced rates of parental activity at the nest, and the production of more broods in a year (Martin, 1995, 2014), and nestlings of species suffering higher levels of nest predation have quieter begging displays (Briskie et al., 1999). At extremely high levels, nest predation may even produce population genetic structure that favours cooperative breeding for kin-selected benefits (Beckerman et al., 2011).

As well as these coarse life-history adaptations, nest predation may also favour fine-scale behavioural adjustments by parents that minimise risk to their offspring. One adjustment that has long been hypothesised is that parents may wait for their partner and synchronise their feeding visits to minimise detection by predators (Sargent, 1993; Raihani et al., 2010). Provisioning visits are events that can betray a nest's location (Skutch, 1949), and combining them by synchronisation effectively halves the risk to offspring that arises from two independent food deliveries. This hypothesis has been supported by empirical results: in three studies, nests that received a greater proportion of synchronised visits were less likely to be depredated (Raihani et al., 2010; Bebbington and Hatchwell, 2016; Leniowski and Wegrzyn, 2018). In this study, we use comparative and experimental data to investigate whether different nest predation regimes explain variation in feeding synchronisation among and within species of passerines in Australasia.

Islands such as New Zealand have suffered disproportionately high numbers of avian extinctions since their colonisation by humans and associated introductions of other predatory mammals (Steadman, 1995; Szabo et al., 2012). A common explanation for these extinctions is that, in an evolutionary sense, bird species on such islands are naive to the threat of these predators and lack adaptations to defend themselves or their offspring. For most of their evolutionary history, the only predators faced by New Zealand birds were other birds such as falcons and owls. In contrast, most other avifaunas are typically subject to predation by a diverse range of avian, mammalian and reptilian predators. Although a variety of adaptations have evolved as a response to avian predators, New Zealand's birds remain poorly adapted to the threat of mammalian predation generally (Duncan and Blackburn, 2005). This situation has been called an "evolutionary trap" (Schlaepfer et al., 2005). For example, many New Zealand birds evolved flightlessness in the absence of mammalian predators and these species were especially susceptible to extinction once these predators arrived (Duncan and Blackburn, 2005). Despite the continuing presence of native predatory birds such as the swamp harrier (Circus approximans) and morepork (Ninox novaeseelandiae), invasive mammals are the dominant nest predators of native New Zealand passerines in the present day (Innes et al., 2010; Starling-Windhof et al., 2011; Remeš et al., 2012). This suggests their introduction would have substantially increased nest predation pressure on native passerines. If synchronisation of nest visits is an evolutionary adaptation against high rates of nest predation, we might predict that New Zealand birds synchronise their visits less than species that coevolved with more diverse predator guilds.

An alternative perspective is that "naïve" island species are not necessarily trapped, and those that survive the appearance of novel threats are capable of adapting to them over short evolutionary timescales (Schlaepfer et al., 2005; Massaro et al., 2008; Urlich, 2015) or even modifying their behaviour immediately (see Fontaine and Martin, 2006). In New Zealand, novel predatory threats to native birds began with the introduction of kiore (Rattus exulans) by Māori in the 1200 s, and intensified when Europeans arrived in the late 1700s, bringing brown and black rats ( $R$. norvegicus and $R$. rattus), house mice (Mus musculus), and domestic cats (Felis catus), and later introducing brushtail possums (Trichosurus vulpecula) and three species of mustelid. These arrivals appear to have driven antipredator adaptations in species like bellbirds (Anthornis melanura) and South Island robins (Petroica australis), because some antipredator behaviours have been recorded in populations of these species exposed to introduced predators, but less so in populations in predator-free sanctuaries (Massaro et al., 2008; White, 2014; Muralidhar, 2017). Thus, some island birds are capable of adaptive evolution, or are sufficiently plastic in their behaviour, to respond to new threats over timescales of (at most) hundreds of years. From this perspective, exposure to introduced mammalian predators may have driven recent evolution of nest visit synchrony in New Zealand bird species.

To evaluate these contrasting predictions, we filmed the nests of 25 species of passerine birds to investigate the extent to which feeding visits to the nest were synchronised and whether the length of coexistence with mammalian predators (short or long evolutionary exposure, or recent exposure to mammalian predators) influences patterns of synchrony. We addressed these aims using three analyses. First, we compared New Zealand's native species with close relatives in Tasmania, and species that were introduced to New Zealand from Europe and share their current environment. The latter two assemblages both coevolved with diverse predators and we predicted they would show an elevated tendency to synchronise visits. In the second analysis, we tested plastic behavioural responses by comparing visit synchrony of species in New Zealand between two neighbouring sites, one where introduced predators were removed and one where they were not. Finally, we compared visit synchrony of bellbirds at both of these mainland New Zealand sites to synchrony on an offshore island where mammalian predators have never been introduced (note that this contrasts to a number of other predatorfree islands in New Zealand, which have only been made so by conservation interventions in recent decades). Bellbirds were previously found to demonstrate adaptive changes in incubation behaviour in response to introduced predators (Massaro et al., 2008), suggesting this species might similarly be able to adjust levels of synchrony in relation to recent changes in predation risk. Based on these analyses, we assessed whether visit synchrony was influenced by predation pressure, and consider the relative roles of phenotypic plasticity vs. evolutionary adaptation. 


\section{METHODS}

\section{Study Outline and Field Sites}

This study had three parts: (1) a comparative analysis of nest visit synchrony across native species in New Zealand vs. Tasmanian and introduced European birds, (2) a comparative analysis of nest visit synchrony across species at two sites in New Zealand, one of which had introduced predators experimentally removed, and (3) a comparison of nest visit synchrony between three populations of bellbirds in New Zealand that differ in predation risk.

For the first comparative analysis, we found and filmed nests of 15 passerine bird species in Kowhai Bush, near Kaikoura, New Zealand, during breeding seasons (September-January) between 2001 and 2006. Kowhai Bush is a 240 ha regenerating lowland forest block, in which the suite of introduced predators common on the New Zealand mainland are all present. The bird species filmed here included six endemic New Zealand species, eight introduced European species and a self-introduced Australian species. The European species were introduced to New Zealand in the nineteenth century but evolved with a range of mammalian predators in their native range. We filmed nests of 10 Tasmanian species in 100 ha of native forest at the Scamander Forest Reserve near St Helens, between September and November in 2004 and 2005. Unlike New Zealand, the native birds in Tasmania evolved with a range of mammalian and reptilian predators, as well as avian predators, and unlike the European species this group contains close phylogenetic relatives of the endemic New Zealand species.

For the second analysis, we used data from nests filmed at Kowhai Bush as above, and filmed additional nests of seven of these species at Waimangarara Bush during breeding seasons between 2004 and 2006. Waimangarara Bush is a 65 ha forest near Kowhai Bush where introduced mammalian predators were historically common, but present in reduced numbers because of trapping and removal during the study period (Massaro et al., 2008; Starling-Windhof et al., 2011). All introduced mammalian predators were targeted for control using 38 tunnel traps (for rats, mustelids and hedgehogs, Erinaceus europaeus) and eight Timms traps (for possums and feral cats). Trapping was supplemented with 52 poison bait stations to further control rodents and possums. A total of 90 stoats (Mustela erminea), 24 ferrets (M. furo), 24 weasels (M. nivalis), 23 possums, 137 rats, 218 hedgehogs, and 32 cats were trapped in this period, and an additional unknown number were killed by poison. Trapping and poisoning did not completely remove the introduced predators, but significantly increased rates of nest success by an average of $59.1 \%( \pm 28.2 \%$ SE) across eight species (range $-6-230 \%$; Starling-Windhof et al., 2011).

For the bellbird analysis, we used data from bellbird nests filmed at Kowhai and Waimangarara as part of the previous analyses, and compared this to data from additional nests filmed on Aorangi Island in the 2004 and 2005 breeding seasons. Aorangi is a 66 ha island off the east coast of Northland, New Zealand, to which exotic predators have never been introduced. Native swamp harriers, moreporks and cuckoos are present, but rarely depredate nests (M.M. unpublished data). As a result, nesting success of bellbirds on Aorangi (65\%) was much higher than that at Waimangara Bush (39\%; predators controlled) and Kowhai Bush (29\%; no predator control). Data on feeding rates from all nest watches in the bellbird dataset were analysed and presented in Massaro et al. (2008), which demonstrated a reduced feeding rate on mainland sites that may be an adaptation to reduce nest visibility to predators. The synchronisation of nest visits in these watches was not previously investigated.

All species in our study are passerines with biparental care and feeding of nestlings (helpers may also have contributed to some feeding trips in some rifleman and Sericornis scrubwren nests). All species also feed their young a diet composed primarily of insects and other invertebrates, although this is supplemented with nectar in the Phylidonyris honeyeaters and with seeds in the Carduelis finches (Higgins et al., 2001, 2006; Higgins and Peter, 2002). It was not possible to determine the number of food items delivered on each parental visit.

\section{Filming Procedure}

All nests were filmed once during the nestling phase, within a day of nestlings breaking their primary pin feathers to control for the stage of offspring development (following Martin et al., 2000; Martin, 2015). Filming began within half an hour of sunrise, except for bellbird nests filmed on Aorangi in 2004, which were filmed later in the morning (see Massaro et al., 2008; the results reported below are qualitatively unaffected by removing these nests from the dataset). Filming continued for approximately $6 \mathrm{~h}$ (mean observation length $=362 \mathrm{~min}, \mathrm{SE}=1 \mathrm{~min}$, range $=$ 317-394 $\min , n=199$ ), during which tapes were changed when they ran out of recording space. This usually meant the $6 \mathrm{~h}$ were separated into two $3 \mathrm{~h}$ recording bouts, but occasionally they were covered by one bout or separated into three or four bouts.

All visits by provisioning adults to the nest were transcribed along with the time they occurred. Each of these visits to the nest were considered to be single events for the purposes of the analysis, with the exception of brooding visits, for which arrival and departure (usually separated by a period of many minutes) were considered two separate events. This reflects that arrivals and departures for brooding events are distinct brief periods of activity separated by the brooding parent sitting inconspicuously on the nest. When nests were visible, brooding visits were assigned by direct observation of adults sitting on the nest; in other nests they were inferred from adults spending an extended period of time in the nest.

Unlike previous studies on colour-ringed populations of single species (Bebbington and Hatchwell, 2016; Leniowski and Wegrzyn, 2018), we were generally unable to determine whether visits close in time (see below) were quickly repeated visits by the same individual, or coordinated visits by different individuals. Each should be functionally equivalent in reducing the number of temporally separate events at the nest that might be visible to predators. In the absence of more detailed information, we expect any patterns of synchrony in our data to arise from a combination of both quick repeat visits and parental coordination.

\section{Quantifying Synchrony of Visits}

For all events except the first in each recording bout, we calculated the interval between it and the previous event. We 
considered synchronised events to be those that occurred within $120 \mathrm{~s}$ of the previous event (Mariette and Griffith, 2015; Ihle et al., 2019); as this window is somewhat arbitrary we also ran analyses using 90 and $150 \mathrm{~s}$ windows, which gave qualitatively similar results (see Ihle et al., 2019). The observed proportion of synchronised events $\left(\mathrm{PSE}_{\mathrm{obs}}\right)$ for a nest watch can be calculated as the observed number of synchronised events $\left(\mathrm{NSE}_{\mathrm{obs}}\right)$, divided by the total number of events (NTE) minus one for each recording bout (NR, usually 2 as we changed tapes once for most nests as described above), as we did not record the interval to the first event of the bout (Equation 1).

$$
P S E=\frac{N S E}{N T E-N R}
$$

An equivalent proportion has been used in previous studies as an index of visit synchrony (Bebbington and Hatchwell, 2016; Leniowski and Wegrzyn, 2018). However, all else being equal, the proportion will increase automatically as visit rate increases: if more events are occurring within a set time period, there is more chance of each happening within $2 \mathrm{~min}$ of the previous. Therefore, $\mathrm{PSE}_{\mathrm{obs}}$ will vary as a function of provisioning rate independently of any active feeding synchronisation on the part of the parents. We might call this "passive synchrony," after Savage et al.'s (2017) distinction between passive and active turntaking in offspring care. It was particularly important to separate passive vs. active synchronisation, as our analyses compared multiple species and populations, which we knew or expected to differ in their provisioning rates (Massaro et al., 2008). Active and passive synchrony can be separated by comparing observed nest watches to simulated nest watches with similar properties, from which we can calculate how much synchrony we would expect to observe by chance (Ihle et al., 2019).

We used simulations to estimate how much passive synchrony was expected to occur simply due to the provisioning rate for each nest watch, as follows: (1) we summed all intervals calculated for a nest watch, giving the total amount of time in seconds that occurred between events in recording bouts within the nest watch; (2) for each nest watch, we simulated a random sequence of the same number of events occurring over the same amount of time using the exponential distribution in R's basic stats package (R Core Team, 2018), giving a sequence of "expected" intervals between events; (3) we counted how many of the resulting intervals were $<120 \mathrm{~s}$, and (4) we repeated this process 100 times for each nest watch and took the median, to give an expected number of synchronised visits. This method assumes that the distribution of intervals is well-modelled by a Poisson process; this is a process that generally describes provisioning data well (Pick et al., 2019), particularly in the absence of enforced delays (refractory periods). These may occur when considering a single individual's behaviour because it needs to find food between visits, but are unlikely to be an issue when considering both parents' visits together as we do here.

The difference between the number of synchronised visits that were observed in a nest watch and the number that were expected to occur "passively" as estimated through the simulations above, provided an estimate of the number that occurred due to active synchronisation by the provisioning adults. If synchronisation is favoured by predation, this should be reflected in such active synchrony. To model this, for each dataset we analysed the number of synchronised visits that occurred in both observed nest watches and expected data (median number from simulations) for each nest in a single model, with the type of data (observed or expected) as a categorical explanatory variable. This term estimated whether synchrony in general occurred more often than expected by chance. The interaction between this term and the effect of interest (e.g., whether species are native to New Zealand) then estimated whether the difference between observed and expected, i.e., the amount of active synchrony, was influenced by that effect. We used this model structure because it has an acceptable type-I error rate for this kind of data (Ihle et al., 2019). Details of each of our individual models are provided below. As the length of observation bouts is taken into account when calculating expected numbers of synchronised visits, our method is robust to the slight variation in the length of observation bouts that occurred due to our sampling design.

\section{Comparative Analyses}

We used a comparative approach to ask whether Tasmanian and introduced European species differed from New Zealand natives in their tendency to synchronise visits. All species from Tasmania in our sample were native, while all introduced European species were filmed in New Zealand. Both Tasmanian and European avifaunas evolved with a diverse predator guild including birds, mammals and reptiles. We classified the silvereye (Zosterops lateralis) in New Zealand, which colonised from Australia in the mid- nineteenth century (Gill et al., 2010), in the same group as the Tasmanian and European species since they shared an evolutionary history with predatory mammals. In contrast, the six species considered New Zealand natives for this analysis are all endemic to New Zealand and evolved in the absence of predatory mammals. We used the same approach to ask whether species in New Zealand differed in their synchrony scores between Kowhai Bush (all introduced predators present) and Waimangarara Bush (introduced predators experimentally removed).

We used Bayesian phylogenetic mixed models implemented in the MCMCglmm R package (Hadfield, 2010) to account for the non-independence of multiple data from the same species, as well as that arising from shared evolutionary history. We modelled number of synchronised visits as a Poisson-distributed response variable. For the first analysis, the exposure of a species to diverse predator guilds over evolutionary time (Tasmanian and European species) or affinity to New Zealand fauna was the two-level categorical fixed effect of interest. For the second analysis, this was site (Kowhai or Waimangarara). Each model also included data type (observed or expected, see above) as a categorical fixed effect; number of visits (scaled and centred) as a numeric fixed effect, because number of visits increases the number that can occur within $2 \mathrm{~min}$; the interaction between data type and the effect of interest (which was the key estimate to determine whether it affected active synchrony, see above), and nest watch identity as a random effect, because each nest watch had both an observed and an expected result associated with it. 
We did not include the effect of visit rate on active synchrony (i.e., the interaction between data type and number of visits), because this term yielded unavoidable false positive results in both related research (Ihle et al., 2019) and exploration of our models using random data.

To estimate and account for the influence of evolutionary relationships, we included a covariance matrix from a phylogenetic tree in the random effect structure of the model. Trees can be readily obtained for subsets of species from the BirdTree.org website (Jetz et al., 2012), but they are not known with certainty. To account for this, we first obtained a distribution of 1,300 phylogenetic trees for our species sets from BirdTree, using the Hackett et al. (2008) backbone. We modified these trees for the first analysis because two of the species included, the New Zealand fantail (Rhipidura fuliginosa) and Australian grey fantail (R. albiscapa), are considered conspecific (as R. fuliginosa) in the BirdTree taxonomy. Following Kenny et al. (2017) we added a tip for $R$. albiscapa to the trees with an artificially short branch length to $R$. fuliginosa, using functions in the phytools $\mathrm{R}$ package (Revell, 2012).

Then, we used methods from Ross et al. (2014) and Downing et al. (2018) to include in our models the uncertainty that is associated with the distribution of trees. We used 1,300 iterations of the Markov chain to build our model in MCMCglmm. Each iteration used the phylogenetic covariance matrix from a different tree and passed its parameter estimates as starting values to the next iteration. We discarded the first 300 iterations of the model as a burn-in and we report the posterior mode $(\beta)$ and $95 \%$ credible intervals (CIs) of parameter estimates from the remaining 1,000 iterations. We assessed model performance by inspecting autocorrelation values and diagnostic plots: for both models, all correlation coefficients were smaller than 0.1 for successive time steps, and plots indicated that all parameters had mixed well.

Phylogeny was allowed to explain variation in both the intercept (number of synchronised visits) and the slope of observed minus expected synchronised visits (active synchrony), in a random regression framework. Priors were modified from Araya-Ajoy and Dingemanse (2017); full details are provided in Supplementary R Script. We calculated phylogenetic heritability $\left(\mathrm{H}^{2}\right)$, equivalent to Pagel's (1999) $\lambda$, for active synchrony as the random variance in the slope that was explained by the phylogenetic covariance matrix, divided by the total random variance in the slope (Hadfield and Nakagawa, 2010; Araya-Ajoy and Dingemanse, 2017). We report $\beta$ and CI for this estimate.

\section{Bellbird Synchrony in Relation to Predation Risk}

In the final part of our study, we asked whether New Zealand bellbirds showed a greater tendency to synchronise visits at sites where they were more exposed to introduced predators. Here, we used a generalised linear mixed model with Poisson error structure implemented in the lme4 R package (Bates et al., 2015). Study site (Kowhai Bush, Waimangarara Bush or Aorangi Island, see descriptions above) was the explanatory variable of

interest. As above, the model also included data type (observed or expected) as a categorical fixed effect, number of visits (scaled and centred) as a numeric fixed effect, the interaction between data type and study site, and nest watch identity as a random effect. We did not include the interaction between data type and number of visits for the same reasons as above (see Comparative Analyses). We assessed statistical significance of fixed effects using type-II Wald $\chi^{2}$-tests in the car $\mathrm{R}$ package (Fox and Weisberg, 2011). Within significant categorical effects, we tested

TABLE 1 | List of species included in our analysis, along with the sample size of nests filmed for each at the sites they were studied.

$\begin{array}{lr}\text { Species } \quad \text { Site } & \begin{array}{r}\text { No. nes } \\ \text { filmed }\end{array}\end{array}$

Rifleman (Acanthisitta chloris)

Bellbird (Anthornis melanura)

New Holland honeyeater (Phylidonyris novaehollandiae)

Crescent honeyeater (Phylidonyris pyrrhopterus)

Grey warbler (Gerygone igata)

Tasmanian thornbill (Acanthiza ewingii)

White-browed scrubwren (Sericornis frontalis)

Tasmanian scrubwren (Sericornis humilis)

Brown creeper (Mohoua

novaeseelandiae)

Golden whistler (Pachycephala pectoralis)

Olive whistler (Pachycephala olivacea) Grey fantail (Rhipidura albiscapa) New Zealand fantail (Rhipidura fuliginosa)

Dusky robin (Melanodryas vittata)

Flame robin (Petroica phoenicea)

South Island robin (Petroica australis)

Silvereye (Zosterops lateralis)

Common starling (Sturnus vulgaris) Song thrush (Turdus philomelos)

Eurasian blackbird (Turdus merula)

Dunnock (Prunella modularis)

Yellowhammer (Emberiza citronella) Chaffinch (Fringilla coelebs) European goldfinch (Carduelis carduelis)

Common redpoll (Carduelis flammea)
Kowhai Bush (NZ)

Kowhai Bush (NZ)

Waimangarara Bush (NZ)

Aorangi I (NZ)

Scamander Forest (Tas)

Scamander Forest (Tas)

Kowhai Bush (NZ)

Waimangarara Bush (NZ)

Scamander Forest (Tas)

Scamander Forest (Tas)

Scamander Forest (Tas)

Kowhai Bush (NZ)

7

8

7

5

2

4

Scamander Forest (Tas)

6

Scamander Forest (Tas)

Scamander Forest (Tas)

Kowhai Bush (NZ)

Waimangarara Bush

Scamander Forest (Tas)

Scamander Forest (Tas)

Kowhai Bush (NZ)

Kowhai Bush (NZ)

Waimangarara Bush (NZ)

Scamander Forest (Tas)

Kowhai Bush (NZ)

Kowhai Bush (NZ)

Waimangarara Bush (NZ)

Kowhai Bush (NZ)

Waimangarara Bush (NZ)

Kowhai Bush (NZ)

Waimangarara Bush (NZ)

Kowhai Bush (NZ)

Kowhai Bush (NZ)

Kowhai Bush (NZ)

Kowhai Bush (NZ)
11

25

1

2

1

1

2

7

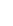

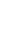

6

3

3

10

2

1

3

13

2

1

9

13

13

9

9

8

3

2

5

4 
differences between categories using pairwise contrasts in the emmeans package (Lenth, 2018), and report the contrast estimate $(\beta$, on the log scale $) \pm$ standard error, $z$ ratio and Tukey-adjusted $P$-value of these.

\section{RESULTS}

\section{Are New Zealand Species Less Synchronised?}

We filmed a total of 103 nests of 15 different species at Kowhai Bush: six New Zealand endemics and nine species considered to have evolved with more diverse predator guilds (eight introduced from Europe and the silvereye, which recently colonised from Australia). We filmed 26 nests of 11 Tasmanian native species at the Scamander Forest Reserve. The complete dataset included 129 nest watches of 25 different species (silvereyes occurred at both sites; see Table 1). Phylogenetic relationships between the species are shown in Figure 1.

The difference between observed and expected synchrony for each nest watch, as a proportion of visit rate, varied both among and within species (Figure 1). For example, riflemen (Acanthisitta chloris) and olive whistlers (Pachycephala olivacea) consistently synchronised visits more often than expected by chance; chaffinches (Fringilla coelebs) and Phylidonyris honeyeaters synchronised visits less often than expected by chance, and species such as silvereyes and common starlings (Sturnus vulgaris) showed a wide range of synchrony scores. Our comparative model of active synchrony yielded three key results. First, there was a moderately strong phylogenetic signal to active synchrony, albeit within a broad confidence range $\left(\mathrm{H}^{2}: \beta=0.503, \mathrm{CI}=0.000-0.700\right)$. Secondly, there was no general tendency across all species for nest watches to contain more synchronised visits than we would expect from their provisioning rate; in fact, there were fewer synchronised visits than expected, though this effect was non-significant (effect of observed data: $\beta=-0.073$, CI $=-0.278-0.187, P=$ 0.566). Thirdly, Tasmanian and introduced European species did not actively synchronise visits more than native New Zealand species: there was no significant interaction between data type and species type, and New Zealand native species in fact showed slightly greater, rather than the predicted reduced, active synchrony (observed data $\times$ New Zealand interaction: $\beta=0.149$, $\mathrm{CI}=-0.090-0.294, P=0.604)$.

There was also, as expected, a strong relationship between overall visit rate and number of synchronised visits (effect of visit rate: $\beta=0.845, \mathrm{CI}=0.698-0.938, P<0.001)$.

\section{Does Experimental Predator Control Influence Visit Synchrony Among Species in New Zealand?}

We filmed 103 nests at Kowhai Bush (all introduced predators present) as above, and 46 nests of seven species at Waimangarara Bush (introduced predators experimentally removed), each of which were present at Kowhai. Thus, the dataset included 149 nest watches of 15 different species (Table 1).
Figure 2 compares differences between the number of observed and expected synchronised visits, as a proportion of visit rate, at Kowhai Bush and Waimangarara Bush for species that were present at both. Similar to the above analysis (which used much of the same data), there was a moderate phylogenetic signal to active synchrony, within broad credible intervals $\left(\mathrm{H}^{2}: \beta=0.287, \mathrm{CI}=0.059-0.638\right)$. As expected, overall visit rate had a clear effect on the number of synchronised visits (effect of visit rate: $\beta=0.860, \mathrm{CI}=0.746-0.946, P$ $<0.001)$. Once this effect was taken into account, across all nests there were no more synchronised visits than expected from provisioning rate (effect of observed data: $\beta=-0.013$, $\mathrm{CI}=-0.186-0.177, P=0.918$ ). Active synchronisation did not differ significantly between the two sites (observed data $\times$ Waimangarara Bush interaction: $\beta=-0.008$, CI $=-0.133-$ 0.096, $P=0.722$ ), although Eurasian blackbirds (Turdus merula) and dunnocks (Prunella modularis) showed greater active synchrony at Kowhai Bush, where predators were not removed (Figure 2).

\section{Do Bellbirds Synchronise Visits More at Sites With Introduced Predators?}

We filmed a total of 43 bellbird nests: 24 on Aorangi Island (no introduced predators present), 11 at Kowhai Bush (all introduced predators present) and eight at Waimangarara Bush (introduced predators experimentally removed).

Differences between observed and expected synchronised visits, as a proportion of visit rate, are plotted for bellbirds by site in Figure 3. There was a significant effect of site on active synchrony (data type $x$ site interaction: $\chi^{2}=$ 6.653, df $=2, P=0.036$ ). Nests at Waimangarara Bush (predators removed) showed more active synchrony (i.e., a greater difference between observed and expected number of synchronised visits), compared to nests on always-predator-free Aorangi Island, though the pairwise difference was marginally non-significant (contrast: $\beta=0.209 \pm 0.091, z=2.304$, $P=0.055$ ). Nests at Kowhai Bush (introduced predators present) also showed a non-significant tendency for more active synchrony than those on always-predator-free Aorangi Island (contrast: $\beta=0.131 \pm 0.082, z=1.597, P=0.247$ ). Nests at Kowhai Bush (introduced predators present) and Waimangarara Bush (predators removed) differed little in active synchrony (contrast: $\beta=0.078 \pm 0.110, z=0.709, P=$ 0.758). A simpler model in which both mainland sites were pooled (such that bellbirds that had been exposed to introduced predators on the mainland were compared with those on Aorangi that had never been exposed to introduced predators) supported the conclusion that there was greater active synchrony on the mainland (data type $\times$ site type interaction: $\chi^{2}=$ 5.403, $\mathrm{df}=1, P=0.020$ ).

There was no significant difference between observed and expected numbers of synchronised visits for bellbirds overall (effect of data type: $\chi^{2}=0.670, \mathrm{df}=1, P=0.413$ ). As expected and as for both models above, visit rate had a clear positive effect on the number of synchronised visits (effect of visit rate: $\chi^{2}=$ 422.290, df $=1, P<0.001)$. 

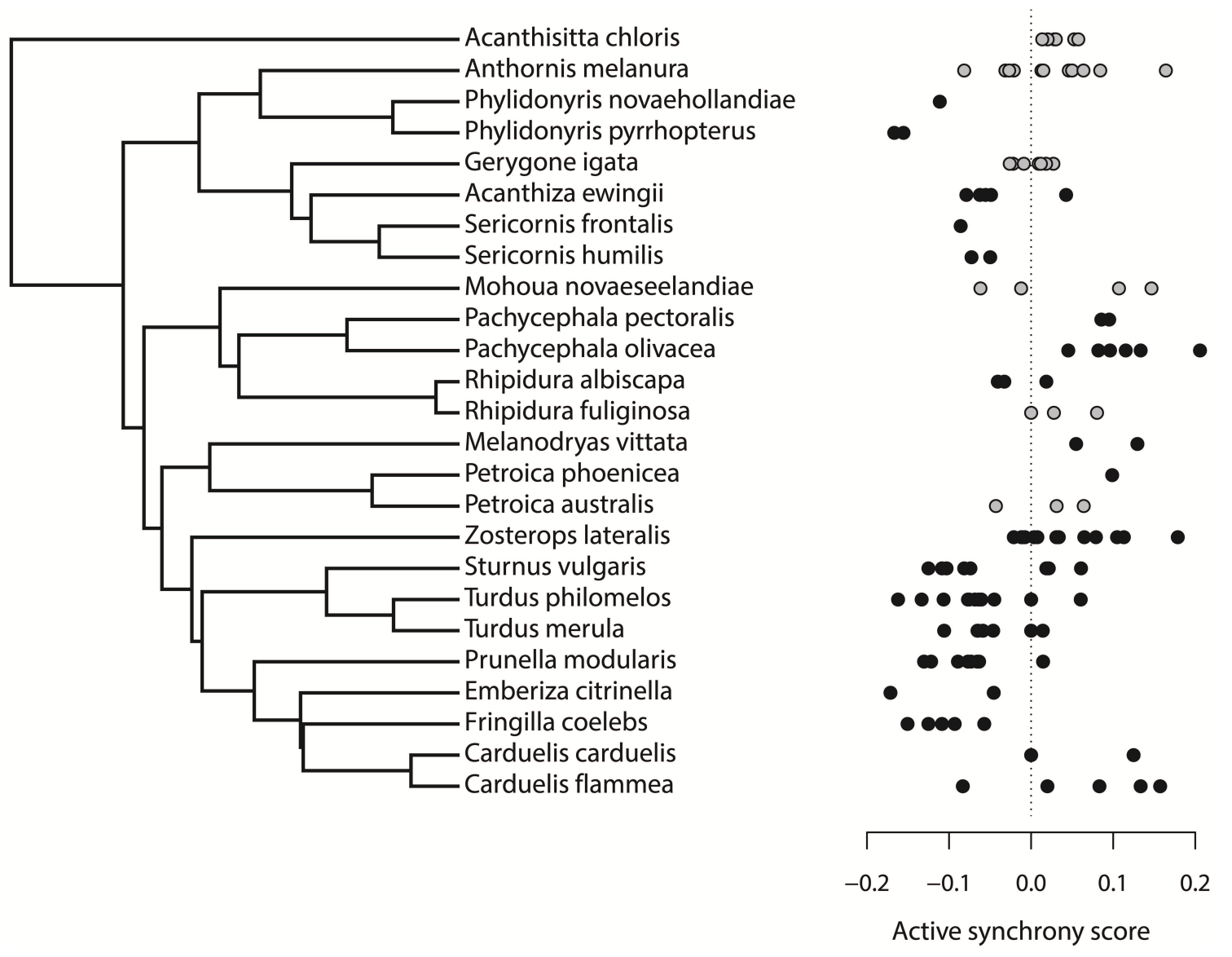

FIGURE 1 | Phylogeny showing relationships between the 25 species used in our comparative analysis, with branch lengths from 1 of 1,300 sample trees downloaded from BirdTree.org (Jetz et al., 2012). Points show an active synchrony score for each nest watch; this is the observed proportion of visits that occurred within 120 s of the previous, minus the median ("expected") proportion from 100 simulated nest watches with the same visit rate. Points are grey for New Zealand species and black for Tasmanian and introduced European species.

\section{DISCUSSION}

We investigated the hypothesis that provisioning parents synchronise their nest visits as an adaptation to reduce the risk of nest predation, using data from nest watches of 25 species in New Zealand and Tasmania, including species and populations exposed to different predation regimes either during the study or in the evolutionary past. In general, nest visit synchrony varied substantially, but nest visits were not more synchronised than we would expect by chance across species. We predicted that variation in nest visit synchrony would vary with predation risk, but we found no general difference between species that have been long exposed to diverse predators vs. species endemic to New Zealand that have evolved until recently in the absence of mammalian nest predators. Synchrony was also generally unaffected by a short-term removal of introduced predators, although two species (the Eurasian blackbird and dunnock) showed the expected pattern. However, in support of the hypothesis, synchrony was higher in mainland populations of the bellbird than a population on an offshore island that never had predatory mammals.

The hypothesis that visit synchrony reduces the risk of predation follows intuitively from predictions and results that suggest predation risk increases with parental activity at the nest (Skutch, 1949; Martin et al., 2000; Muchai and Du Plessis, 2005; Martin and Briskie, 2009). It also has support from empirical studies of single species, in which nests where parents visited more synchronously were less likely to be depredated (Raihani et al., 2010; Bebbington and Hatchwell, 2016; Leniowski and Wegrzyn, 2018). In our study, there was some evidence that predation risk may have influenced provisioning patterns in bellbirds, as populations that coexist with mammalian nest predators on the mainland synchronised their visits more than a population on predator-free Aorangi Island. Previous analyses of these data revealed that the mainland New Zealand populations reduced their activity around the nest by making fewer incubation changeovers and provisioning visits (Massaro et al., 


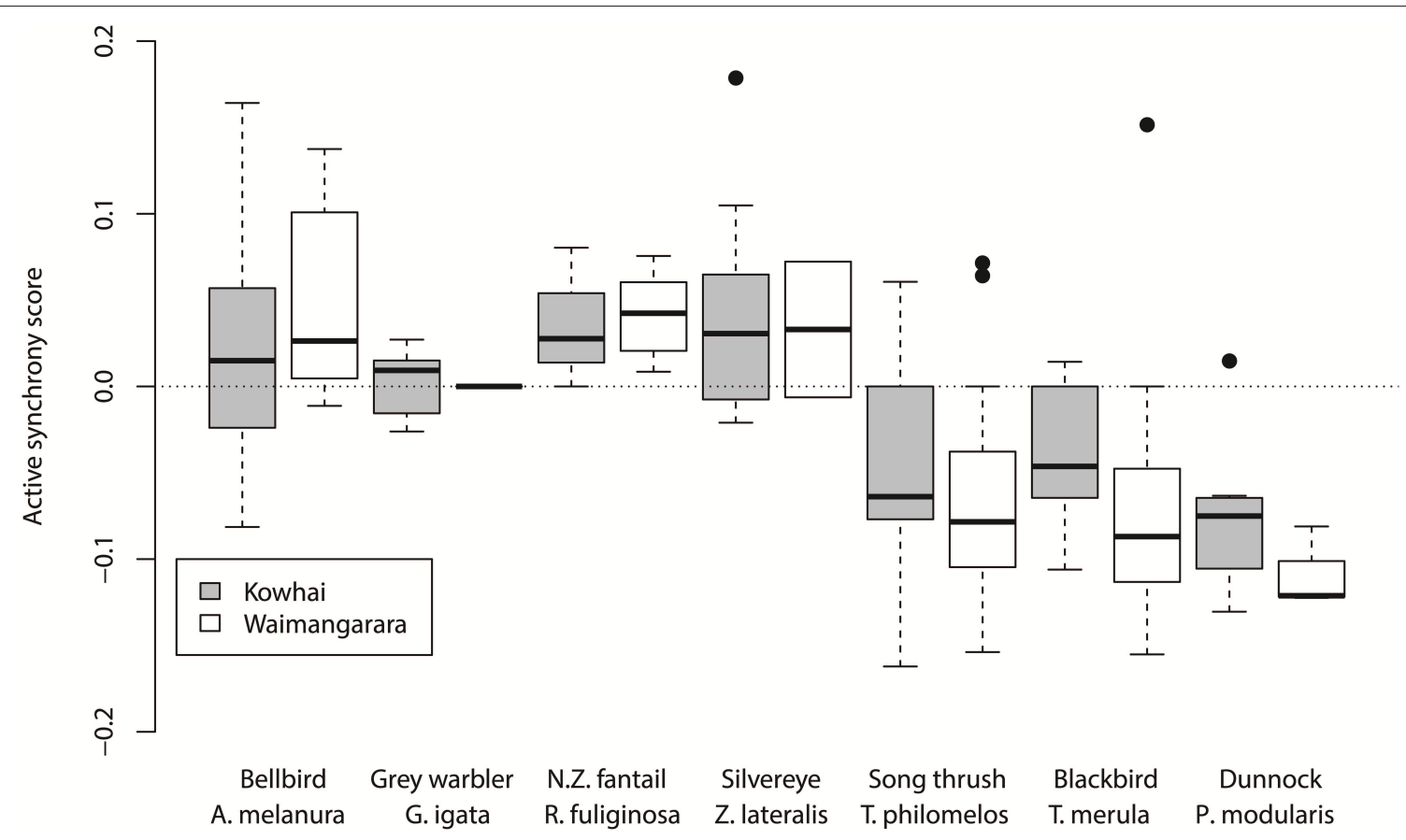

FIGURE 2 | A comparison of active synchrony scores between nest watches at Waimangarara Bush, from which predatory mammals were removed during the study period, and Kowhai Bush, from which they were not, for species recorded at both. Scores are observed proportions of visits that occurred within $120 \mathrm{~s}$ of the previous, minus the median ("expected") proportion from 100 simulated nest watches with the same visit rate. Full species scientific names are provided in Table 1 and Figure 1.

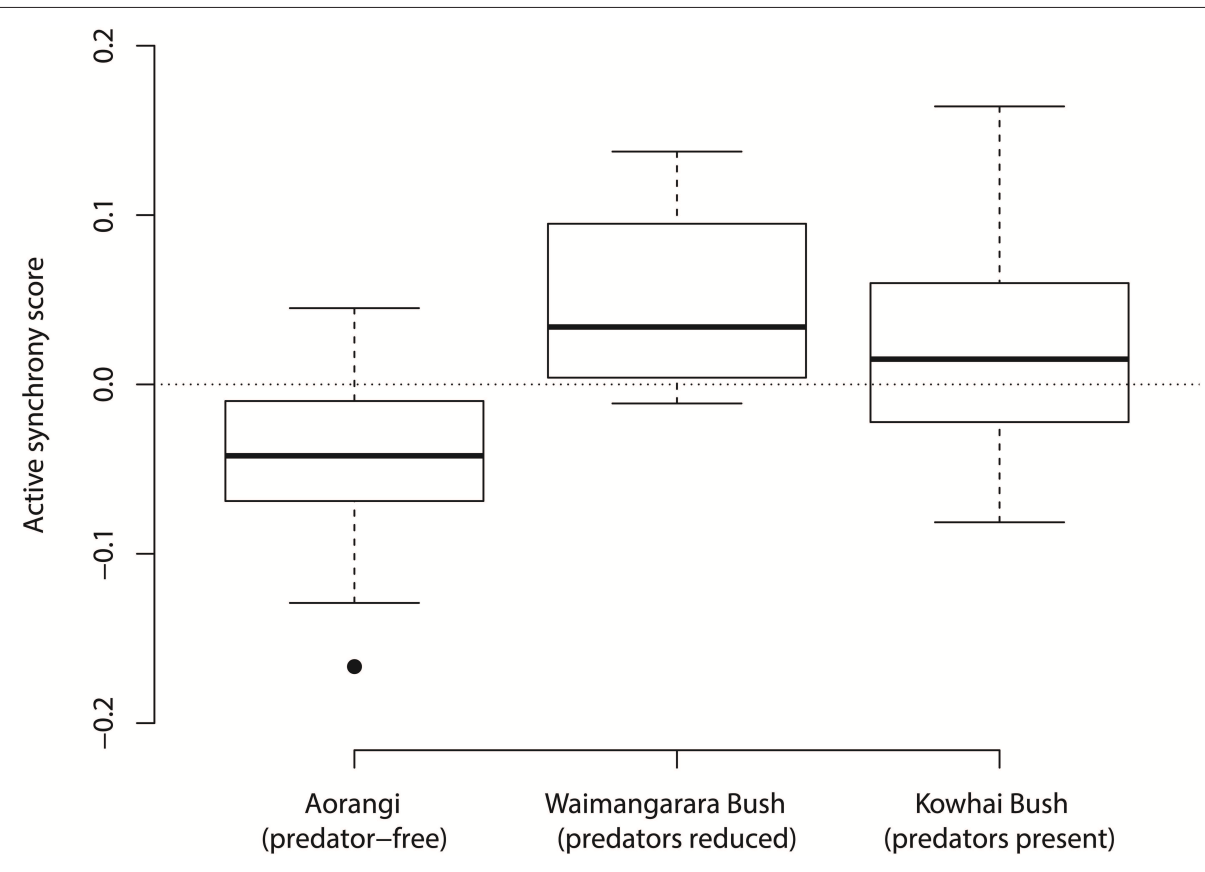

FIGURE 3 | The distribution of synchrony scores from bellbird (Anthornis melanura) nest watches at three sites in New Zealand; these are observed proportions of visits that occurred within $120 \mathrm{~s}$ of the previous, minus the median ("expected") proportion from 100 simulated nest watches with the same visit rate. Aorangi is an island to which predatory mammals have never been introduced. Numbers of predatory mammals at Waimangarara Bush were reduced by trapping during the study period. Predatory mammals were present and not trapped at Kowhai Bush. 
2008). More frequent synchronisation of visits may be a further adaptation to the pressures posed by introduced predators.

The similarity of synchrony scores between the Kowhai Bush and Waimangarara Bush sites suggests this adaptation is more likely to be a short-term evolutionary response than one arising from flexibility in behaviour. One of the sites (Waimangarara) had reduced predator pressure relative to the other, but only over a time period simultaneous with our study. Therefore, if provisioning birds were modifying their synchrony flexibly based on cues to the likely level of predation, we would have expected them to synchronise visits less often at Waimangarara Bush than Kowhai Bush. We found no evidence for this in bellbirds (see Figure 3), nor overall across species (see Figure 2). Although previous studies have documented breeding birds adjusting traits such as egg size, clutch size and provisioning rate in response to manipulated predation pressure (Fontaine and Martin, 2006; Ibáñez-Alamo et al., 2015), this was not generally the case for visit synchrony here. A possible explanation is that synchrony is unlikely to incur costs as great as the abovementioned traits, and therefore there may be greater pressure to increase synchrony in the presence of predators than reduce it in their absence. However, it is worth noting that Eurasian blackbirds, dunnocks, and (marginally) song thrushes (Turdus philomelos) showed differences in the predicted direction (Figure 2). This is intriguing as these are European species that coevolved with the mammalian predators introduced to New Zealand, and may have adjusted their behaviour in response to their presence. Although not supported statistically by our results (we had insufficient data to test it robustly), this would be an interesting trend to explore in future research.

Despite the suggestion that predation risk influenced visit synchrony for bellbirds, we found little evidence that it explained variation among species. First, species that coevolved with a suite of nest predators from more diverse guilds showed no more active synchrony of visits than "naive" New Zealand endemics. As exemplified by bellbirds, this may reflect a recentlyevolved increase in visit synchrony among New Zealand species, following the introduction of predatory mammals. A related but distinct explanation is that New Zealand's present-day native avifauna has retained a non-random sample of its species since human colonisation, specifically those with adaptations (such as, perhaps, nest visit synchrony) that have made them resilient to introduced predators (Remeš et al., 2012). Alternatively, visit synchrony might be mostly constrained by other ecological or biological factors, such as foraging behaviour (see Van Rooij and Griffith, 2013 and discussion below), with predation pressure playing only a minor role in its expression. Finally, it is possible also that dominant predators have a strong influence on evolution of this behaviour. Native New Zealand species in fact exhibited some of the highest active synchrony scores in our study (Figures 1, 2). Avian predators primarily use visual cues to locate their prey, and so patterns of synchrony may be more advantageous as an adaptation to this predatory guild. In contrast, Tasmanian and European species (in their native range) must also contend with mammalian and reptilian predators, which use olfactory cues to locate prey and are often nocturnal when foraging, and so may derive little benefit from sychronisation during the day. Whether selection favours the evolution of synchrony may thus depend upon the composition of the predator guild and the likelihood these predators use activity cues to locate nests. Nevertheless, the differences between bellbird populations we observed suggest that changes to this guild and intensification of predation pressure can favour increases in synchrony.

A second, surprising result of our comparative analyses was that in general, provisioning adults did not synchronise their visits more often than would be expected to occur by chance for observations with the same provisioning rate. This contrasts with previous studies of zebra finches (Taenopygia guttata) and house sparrows (Passer domesticus), both of which synchronised visits significantly more often than expected by chance (Mariette and Griffith, 2015; Ihle et al., 2019). We found considerable variation among taxa, with a moderately high phylogenetic heritability, but across 24 species only riflemen and olive whistlers consistently synchronised visits more often than expected (Figure 1). Following our study, non-random patterns of synchronised visits can be considered the exception rather than the norm among species where this has been tested.

One feature of species with "exceptionally" synchronised visits may be a tendency for pairs to forage together, which naturally leads to (although does not explain all instances of) synchronised visits in zebra finches (Mariette and Griffith, 2015), and also occurs in riflemen (N.K. pers. obs.). Further aspects of foraging strategies could influence the costs and benefits associated with synchrony. For example, parents foraging in different areas (e.g., to limit competition) may be unable to monitor one another's behaviour without wasting considerable time waiting around the nest, while for parents foraging together (e.g., to minimise risk of their own predation), synchrony should be easier to achieve. Of course, different foraging strategies employed by different species or in different environments may themselves be influenced by the risk of predation. Food availability may also influence parents' ability to synchronise: if foraging is timeconsuming, waiting for a partner is likely to be more costly than if food can be found quickly. Food supplementation experiments would be a useful way of testing the importance of this for explaining synchronisation.

The little evidence we found for active synchrony across species, despite the indication from previous studies that synchrony reduces predation risk (Raihani et al., 2010; Bebbington and Hatchwell, 2016; Leniowski and Wegrzyn, 2018), raises the possibility that evenly spaced visits provide their own unrecognised benefits that trade off against those of synchrony. For example, the delivery of multiple food items simultaneously followed by long periods of no deliveries may provide less efficient energy use by young, and regular feeding visits may improve nestling growth (Wojczulanis-Jakubas et al., 2018). It is worth noting that if such advantages allow nestlings to fledge sooner, this will also reduce the probability of nest predation (as it is a time-dependent event), improving the fitness of provisioning parents (Martin et al., 2018). Such benefits may outweigh antipredator benefits of synchrony in cases where visit rates do not increase risk, or visit rates are so low that synchrony is relatively unimportant. This possibility is consistent 
with our bellbird results: synchrony in the absence of predators was significantly lower than random, and with predators it increased to a level similar to that expected at random. In other words, rather than driving highly synchronised visit patterns, pressure to avoid predators could shift visit patterns away from an active asynchrony that would otherwise be optimal, to more synchronised patterns that look closer to random.

In summary, we have found some evidence consistent with the hypothesis that visit synchrony is an adaptation against predators among populations of the New Zealand bellbird, which have had different predation regimes for approximately 800 years. In contrast, we found little evidence across multiple species that synchrony is associated with predation risk in the deeper evolutionary past, or that synchrony responds immediately to predator removal as would be expected if it were a plastic phenotype. Further, we found no evidence that synchrony occurs more often than random across species, despite its potential adaptive benefit, and in contrast with previous studies of single species. We conclude that species in the three passerine assemblages we studied do not generally show non-random patterns of synchronised visits. We speculate that an even spacing of feeding visits (the opposite pattern) may carry its own adaptive benefit, not recognised by previous studies focusing on synchrony. Finally, variation in synchrony needs to be examined across a broader range of species and nest predation conditions, with further research into when, where and why it occurs.

\section{DATA AVAILABILITY STATEMENT}

The raw data supporting the conclusions of this manuscript will be made available by the authors, without undue reservation, to any qualified researcher upon contact with the corresponding author.

\section{ETHICS STATEMENT}

This study was carried out with approval and in accordance with the recommendations of the University of Canterbury's Animal Ethics Committee and the New Zealand Department of Conservation.

\section{REFERENCES}

Araya-Ajoy, Y. G., and Dingemanse, N. J. (2017). Repeatability, heritability, and age-dependence of seasonal plasticity in aggressiveness in a wild passerine bird. J. Anim. Ecol. 86, 227-238. doi: 10.1111/1365-2656.12621

Bates, D., Maechler, M., Bolker, B., and Walker, S. (2015). Fitting linear mixed-effects models using lme4. J. Stat. Soft 67, 1-48. doi: 10.18637/jss. v067.i01

Bebbington, K., and Hatchwell, B. J. (2016). Coordinated parental provisioning is related to feeding rate and reproductive success in a songbird. Behav. Ecol. 27, 652-659. doi: 10.1093/beheco/arv198

Beckerman, A. P., Sharp, S. P., and Hatchwell, B. J. (2011). Predation and kin-structured populations: an empirical perspective on the evolution of cooperation. Behav. Ecol. 22, 1294-1303. doi: 10.1093/beheco/arr131

\section{AUTHOR CONTRIBUTIONS}

JB, MM, and TM collected the data. NK analyszed the data and wrote the first draft of the manuscript, to which all coauthors contributed revisions.

\section{FUNDING}

This project was funded by grants to JB from the Association for the Study of Animal Behaviour, Brian Mason Scientific and Technical Trust, Percy Sladen Memorial Fund, Royal Society of New Zealand Marsden Fund, and University of Canterbury, and grants to MM from the University of Canterbury and the Foundation for Research, Science and Technology (UOCX0601). TM was supported by the National Science Foundation (DEB-1651283, IOS-1656120); this work was conducted under auspices of University of Montana IACUC \#059-10TMMCWRU. Any use of trade, firm, or product names is for descriptive purposes only and does not imply endorsement by the U.S. Government.

\section{ACKNOWLEDGMENTS}

Many thanks to Malika Ihle for sharing unpublished work and making helpful comments that informed our data analysis. Thanks to Joel Pick and two reviewers for thoughtful comments that improved the content of this manuscript. Thanks also to Lainie Berry, Lucy Birkenshaw, James Muir, Danielle Shanahan, Lisa Shorey, Amanda Starling-Windhof, Sabrina Taylor, Andrew Thomas, and Elinor Watson for their contributions to collecting this dataset. Our study in Waimangarara Bush would not have been possible without the continued dedication of Barry Dunnett to control introduced predators and protect the native birds of this forest.

\section{SUPPLEMENTARY MATERIAL}

The Supplementary Material for this article can be found online at: https://www.frontiersin.org/articles/10.3389/fevo. 2019.00389/full\#supplementary-material

Briskie, J. V., Martin, P. R., and Martin, T. E. (1999). Nest predation and the evolution of nestling begging calls. Proc. Roy. Soc. B 266, 2153-2159. doi: 10.1098/rspb.1999.0902

Downing, P. A., Griffin, A. S., and Cornwallis, C. K. (2018). Sex differences in helping effort reveal the effect of future reproduction on cooperative behaviour in birds. Proc. Roy. Soc. B 285:20181164. doi: 10.1098/rspb.2018.1164

Duncan, R. P., and Blackburn, T. M. (2005). Extinction and endemism in the New Zealand avifauna. Glob. Ecol. Biogeogr. 13, 509-517. doi: 10.1111/j.1466-822X.2004.00132.x

Fontaine, J. J., and Martin, T. E. (2006). Parent birds assess nest predation risk and adjust their reproductive strategies. Ecol. Lett. 9, 428-434. doi: 10.1111/j.1461-0248.2006.00892.x

Fox, J., and Weisberg, S. (2011). An R Companion to Applied Regression, 2nd Edn. Thousand Oaks, CA: Sage. 
Gill, B. J., Bell, B. D., Chambers, G. K., Medway, D. G., Palma, R. L., Scofield, R. P., et al. (2010). Checklist of the birds of New Zealand, Norfolk and Macquarie islands, and the Ross Dependency, Antarctica. Wellington: Te Papa Press.

Hackett, S. J., Kimball, R. T., Reddy, S., Bowie, R. C. K., Braun, E. L., Braun, M. J., et al. (2008). A phylogenomic study of birds reveals their evolutionary history. Science 320, 1763-1768. doi: 10.1126/science.1157704

Hadfield, J. D. (2010). MCMC methods for multi-response generalized linear mixed models: the MCMCglmm R package. J. Stat. Softw. 33, 1-22. doi: $10.18637 /$ jss.v033.i02

Hadfield, J. D., and Nakagawa, S. (2010). General quantitative genetic methods for comparative biology: phylogenies, taxonomies and multi-trait models for continuous and categorical characters. J. Evol. Biol. 23, 494-508. doi: 10.1111/j.1420-9101.2009.01915.x

Higgins, P. J., and Peter, J. M. (eds.). (2002) Handbook of Australian, New Zealand and Antarctic Birds 6. Melbourne, VIC: Oxford University Press.

Higgins, P. J., Peter, J. M., and Cowling, S. J. (2006). Handbook of Australian, New Zealand and Antarctic Birds 7. Melbourne, VIC: Oxford University Press.

Higgins, P. J., Peter, J. M., and Steele, W. K. (2001). Handbook of Australian, New Zealand and Antarctic Birds 5. Melbourne, VIC: Oxford University Press.

Ibáñez-Alamo, J. D., Magrath, R. D., Oteyza, J. C., Chalfoun, A. D., Haff, T. M., Schmidt, K. A., et al. (2015). Nest predation research: recent findings and future perspectives. J. Ornithol. 156(Suppl. 1), 247-262. doi: $10.1007 /$ s10336-015-1207-4

Ihle, M., Pick, J. L., Winney, I. S., Nakagawa, S., and Burke, T. (2019). Measuring up to reality: null models and analysis simulations to study parental coordination in provisioning offspring. Front. Ecol. Evol. 7:142. doi: 10.3389/fevo.2019.00142

Innes, J., Kelly, D., Overton, J. M., and Gillies, C. (2010). Predation and other factors currently limiting New Zealand forest birds. N.Z. J. Ecol. 34, 86-104.

Jetz, W., Thomas, G. H., Joy, J. B., Hartmann, K., and Mooers, A. O. (2012). The global diversity of birds in space and time. Nature 491, 444-448. doi: $10.1038 /$ nature 11631

Kenny, E., Birkhead, T. R., and Green, J. P. (2017). Allopreening in birds is associated with cooperation over offspring care and stable pair bonds across years. Behav. Ecol. 28, 1142-1148. doi: 10.1093/beheco/arx078

Leniowski, K., and Wegrzyn, E. (2018). Synchronisation of parental behaviours reduces the risk of nest predation in a socially monogamous passerine bird. Sci. Rep. 8:7385. doi: 10.1038/s41598-018-25746-5

Lenth, R. (2018). emmeans: Estimated Marginal Means, Aka Least-Squares Means. $\mathrm{R}$ package version 1.3.0. Available online at: https://cran.r-project.org/package= emmeans

Mariette, M. M., and Griffith, S. C. (2015). The adaptive significance of provisioning and foraging coordination between breeding partners. Am. Nat. 185, 270-280. doi: 10.1086/679441

Martin, T. E. (1995). Avian life history evolution in relation to nest sites, nest predation, and food. Ecol. Monogr. 65, 101-127. doi: 10.2307/2937160

Martin, T. E. (2014). A conceptual framework for clutch-size evolution in songbirds. Am. Nat. 183, 313-324. doi: 10.1086/674966

Martin, T. E. (2015). Age-related mortality explains life history strategies of tropical and temperate songbirds. Science 349, 966-970. doi: 10.1126/science.aad1173

Martin, T. E., and Briskie, J. V. (2009). Predation on dependent offspring: a review of the consequences for mean expression and phenotypic plasticity in avian life history traits. Ann. N.Y. Acad. Sci. 1168, 201-217. doi: 10.1111/j.1749-6632.2009.04577.x

Martin, T. E., Scott, J., and Menge, C. (2000). Nest predation increases with parental activity: separating nest site and parental activity effects. Proc. R. Soc. B 267, 2287-2293. doi: 10.1098/rspb.2000.1281

Martin, T. E., Tobalske, B., Riordan, M. M., Case, S. B., and Dial, K. P. (2018). Age and performance at fledging are a cause and consequence of juvenile mortality between life stages. Sci. Adv. 4:eaar1988. doi: 10.1126/sciadv.aar1988

Massaro, M., Starling-Windhof, A., Briskie, J. V., and Martin, T. E. (2008). Introduced mammalian predators induce behavioural changes in parental care in an endemic New Zealand bird. PLOS ONE 3:e2331. doi: 10.1371 /journal.pone.0002331

Muchai, M., and Du Plessis, M. A. (2005). Nest predation of grassland bird species increases with parental activity at the nest. J. Av. Biol. 36, 110-116. doi: $10.1111 /$ j.0908-8857.2005.03312.x
Muralidhar, A. (2017). Adaptive anti-predator behaviour of South Island robin (Petroica australis australis) in mammalian predator-free and predator-dense regions (M.Sc. thesis). Dunedin: University of Otago.

Pagel, M. (1999). Inferring the historical patterns of biological evolution. Nature 401, 877-884. doi: 10.1038/44766

Pick, J. L., Khwaja, N., Spence, M. A., Ihle, M., and Nakagawa, S. (2019). Counter culture: causes, extent and solutions of systematic bias in the analysis of behavioural counts. EcoEvoRxiv. doi: 10.32942/osf.io/jq9n6

R Core Team (2018). R: A Language and Environment for Statistical Computing. Vienna: R Foundation for Statistical Computing. Available online at: https:// www.R-project.org

Raihani, N. J., Nelson-Flower, M. J., Moyes, K., Browning, L. E., and Ridley, A. R. (2010). Synchronous provisioning increases brood survival in cooperatively breeding pied babblers. J. Anim. Ecol. 79, 44-52. doi: 10.1111/j.1365-2656.2009.01606.x

Remeš, V., Matysioková, B., and Cockburn, A. (2012). Nest predation in New Zealand songbirds: exotic predators, introduced prey and long-term changes in predation risk. Biol. Cons. 148, 54-60. doi: 10.1016/j.biocon.2012.01.063

Revell, L. J. (2012). phytools: an R package for phylogenetic comparative biology (and other things). Meth. Ecol. Evol. 3, 217-223. doi: 10.1111/j.2041-210X.2011.00169.x

Ross, L., Gardner, A., Hardy, N., and West, S. A. (2014). Ecology, not the genetics of sex determination, determines who helps in eusocial populations. Curr. Biol. 23, 2383-2387. doi: 10.1016/j.cub.2013.10.013

Sargent, S. (1993). Nesting biology of the yellow-throated euphonia: large clutch size in a neotropical frugivore. Wils. Bull. 105, 285-300.

Savage, J. L., Browning, L. E., Manica, A., Russell, A. F., and Johnstone, R. A. (2017). Turn-taking in cooperative offspring care: by-product of individual provisioning behavior or active response rule? Behav. Ecol. Sociobiol. 71:162. doi: 10.1007/s00265-017-2391-4

Schlaepfer, M. A., Sherman, P. W., Blossey, B., and Runge, M. C. (2005). Introduced species as evolutionary traps. Ecol. Lett. 8, 241-246. doi: 10.1111/j.1461-0248.2005.00730.x

Skutch, A. F. (1949). Do tropical birds rear as many young as they can nourish? IBIS 91, 430-455. doi: 10.1111/j.1474-919X.1949.tb02293.x

Starling-Windhof, A., Massaro, M., and Briskie, J. V. (2011). Differential effects of exotic predator-control on nest success of native and introduced birds in New Zealand. Biol. Inv. 13, 1021-1028. doi: 10.1007/s10530-010-9886-5

Steadman, D. W. (1995). Prehistoric extinctions of Pacific island birds: biodiversity meets zooarchaeology. Science 267, 1123-1131. doi: $10.1126 /$ science.267.5201.1123

Szabo, J. K., Khwaja, N., Garnett, S. T., and Butchart, S. H. M. (2012). Global patterns and drivers of avian extinctions at the species and subspecies level. PLOS ONE 7:e47080. doi: 10.1371/journal.pone.0047080

Urlich, S. C. (2015). What's the end-game for biodiversity: is it time for conservation evolution? N.Z. J. Ecol. 39, 133-142.

Van Rooij, E. P., and Griffith, S. C. (2013). Synchronised provisioning at the nest: parental coordination over care in a socially monogamous species. PeerJ 1:e232. doi: $10.7717 /$ peerj. 232

White, R. (2014). Response of New Zealand birds to the presence of novel predators (M.Sc., thesis). Christchurch: University of Canterbury.

Wojczulanis-Jakubas, K., Araya-Salas, M., and Jakubas, D. (2018). Seabird parents provision their chick in a coordinated manner. PLOS ONE 13:e0189969. doi: 10.1371/journal.pone.0189969

Conflict of Interest: The authors declare that the research was conducted in the absence of any commercial or financial relationships that could be construed as a potential conflict of interest.

Copyright $\odot 2019$ Khwaja, Massaro, Martin and Briskie. This is an open-access article distributed under the terms of the Creative Commons Attribution License (CC $B Y)$. The use, distribution or reproduction in other forums is permitted, provided the original author(s) and the copyright owner(s) are credited and that the original publication in this journal is cited, in accordance with accepted academic practice. No use, distribution or reproduction is permitted which does not comply with these terms. 